\title{
The Second International Cancer Congress
}

$\mathrm{T}^{\mathrm{H}}$ HE Second International Cancer Congress, held at Brussels under the auspices of L'Union Internationale contre le Cancer, terminated on September 28. Between three and four hundred surgeons, physicians, radiologists and research workers, drawn from forty-seven different countries, were in attendance, and were welcomed by M. Lerat, president of the Congress; by M. Justin Godart, president of L'Union Internationale contre le Cancer ; and by M. Vandervelde, (Belgian) Minister of Health, in the presence of H.M. The King of the Belgians.

Great Britain was officially represented by Dr. W. Cramer, Col. A. B. Smallman, Mr. Sampson Handley, Mr. J. J. Shaw, and Mr. Cecil Rowntree. There was also a large group of workers from the great research centres, which included Dr. W. E. Gye, Prof. E. L. Kennaway, Prof. J. W. Cook, Dr. R. D. Passey, Prof. Mathew Stewart, Dr. Dorothy Russell, Dr. P. D. Peacock, Dr. Donaldson, and Mr. Stanford Cade.

The Belgian Committee, to whom the organization of the Congress had been entrusted by the Union Internationale, by a wealth of private and public hospitality did much to establish a degree of intimacy between the nationals of so many diverse countries, and added greatly to the success of the Congress.

Among the more notable official occasions was a reception by the Prime Minister and Mme. van Zeeland held at the beautiful Musée Cinquantenaire; and a banquet at which speeches were made by representatives of Germany, France, Great Britain, Italy, Spain, Greece and Sweden expressing their appreciation of the great scientific and social success of the Congress. During the latter, one delegate felt that song was the only suitable medium with which to express his feelings, and brought down the house with his delightful rendering of "Qui ne sait boire, ne sait rien".

But perhaps the most interesting event--in any event so far as the delegates from the British Empire were concerned-was the reception on the last evening at the Fondation Universitaire, when the opportunity was taken to present to Profs. Kennaway and Cook the prize award of the Union Internationale. The allocation of this prize to the two English research workers was unanimously voted at a meeting of the Council of the Union. It consists of a sum of money and a quantity of radium, generously placed at the disposal of the Union Internationale by the Union Miniere [see Nature, Oct. 3, p. 579].

In addition to a large number of independent papers, thirty-five official reports were presented. All the different aspects of the cancer problem came under consideration, and the subjects ranged from the demonstration of micro-puncture of cells by ultra-violet rays, to the provision of hospital accom. modation for incurable cancer patients.

For the presentation of the communications, six different sections had been created, and by skilful organization it had been arranged that papers relating to allied subjects were read in one section, and so far as possible at the same meeting. One of the most interesting meetings was a discussion on carcinogenesis, in which Profs. Kennaway and Cook spoke on chemical compounds as carcinogenic agents, and Dr. Gye on tumours transmissible with viruses. At a subsequent meeting, Prof. F. Pentimalli (Florence) submitted a report on the nature of the agent present in two filtrable fowl tumours. The hereditary factors in cancer were discussed by Dr. Clara Lynch (New York), Prof. Maud Slye (Chicago), Dr. L. Kreyberg (Oslo), Prof. Nadine Dobrovolskaia-Zavadskaia (Paris), Prof. R. Korteweg (Amsterdam), Dr. Wilhelmina Dunning (New York), and Prof. A. Hintze (Berlin).

Communications on the experimental investigation of cancer were submitted by Dr. P. R. Peacock (Glasgow), Prof. R. D. Passey (Leeds), Prof. J. McIntosh (London), Dr. O. Schurch (Winterthur), Prof. Oberndorfer (Istanboul), Dr. I. Berenblum (Leeds), and others. The interesting new subject of transplantable fibro-adenomata of rats and their transformation into sarcomata was discussed by Dr. Ch. Oberling (Paris), and Dr. J. Heiman (New York). Mr. Sampson Handley (London) presented his thesis on the etological importance of lymph stasis.

On the subject of the diagnosis of cancer, Dr. J. Ewing (New York) read a report on problems in histological diagnosis, whilst Prof. L. Hirszfeld (Warsaw), Prof. P. Rondoni (Milan) and Prof. P. Del Rio Hortega (who had specially travelled from Madrid to attend the Congress), discussed the serological and sero-cytological diagnosis of cancer. Dr. Dorothy Russell showed her instructive film demonstrating the tissue culture of gliomata.

The papers read in the section of radiotherapy by Prof. F. Carter Wood (New York), Prof, H. R. Schniz (Zurich), and Dr. L. Mallet (Paris) gave an indication of the progress made in this important branch of cancer therapy as a result of a better understanding of the mode of action of $\mathrm{X}$-rays and radium. By a modification of the previous technique, Schinz has succeeded in obtaining in tumours of the mesopharynx, in which previously radiotherapy had been a failure, a remarkably high percentage of fiveyear cures. Schinz also emphasized the importance of radiotherapy as a palliative measure in cancer. This aspect was dealt with in greater detail in the communication of $\mathrm{Dr}$. Mallet. $\mathrm{He}$ has applied systematically tele-X-ray therapy to patients in advanced stages of cancer, by exposing large parts of the body at long distances. He showed by numerous illustrations that his method enables him to check the progress of the disease in advanced stages of cancer of the uterus and of the csophagus, and also in metastases in bones and lungs. Mr. Stanford Cade gave an account of the results obtained by the Curie therapy in pharyngeal cancer.

In the Social Section, the importance of statistics as a scientific method for the investigation of the etiological factors of cancer in man was emphasized in reports by Dr. L. I. Dublin (New York), Dr. W. Cramer (London), and Dr. S. Peller (Jerusalem). Some of the American and German delegates, believing that a morbidity statistic would advance our knowledge, submitted a resolution that the compulsory notification of cancer is advisable from this point of view, and that the Union Internationale should appoint a committee to consider this question. 
The incidence of cancer in different races was discussed by Prof. C. Bonne (Batavia), and M. J. A. des Ligneris (South Africa).

The thorny problem of the medical treatment of cancer was discussed in numerous communications. One of these methods which, described as a poly. valent hormonetherapy, had received a good deal of notice in the Continental press, was submitted to a devastating criticism; while the more serious attempts by Prof. E. Freund and Dr. Kaminer of Vienna, which were frankly admitted to be mainly of a palliative nature, were listened to with respectful scepticism.

The general feeling among the delegates was that definite progress has been made both in our under. standing of the disease and in the methods of treat. ment; and that a continuation of this progress is assured. This feeling found expression in the con. clusion submitted at the final meeting, in which it was stated, for the first time officially, that cancer is a disease which is not only curable, but also, within limits, preventable.

\section{National Smoke Abatement Exhibition}

$\mathrm{D}^{\mathrm{n}}$ URING October, an exhibition and conference is being held under the auspices of the National Smoke Abatement Society in the Science Museum, South Kensington. The interesting Handbook (Pp. 78. Price 6d.) published by the Society, the offices of which are at 36 King Street, Manchester, contains twelve articles on various aspects, which are reinforced by another dozen addresses at the Conference held at the Science Museum on October 14-17. Dr. des Voeux, reviewing the smoke abatement movement, mentioned that an exhibition of ap. pliances was held in 1885. Actually one was held still earlier, in November 1881, under most influential auspices and also in South Kensington (NATURE, 25, 219 ; 1882). The writer has been informed that the organizers were prosecuted for causing a smoke nuisance. Many would be interested to Jearn that a grate designed by Sir W. Siemens for burning coke and fitted with a gas burner for ignition was a prominent exhibit (NATURE, 23, 25; 1881). The promoters of the 1881 exhibition would have been surprised to learn that a problem which they understood would still await solution after half a century.

Technically, of course, a solution is possible, but the obstacle is a lack of will. Generally speaking, enthusiasts for smoke abatement lack power and influence commensurate with their knowledge and vision. They control neither politics nor finance. As a result it is rare, even now, to find in local government any party making atmospheric cleanliness a primary object of policy. Alteration may, however, come soon. It may be realized by property owners that upper floors of buildings in central urban areas might serve as attractive residential quarters if the air were freed from smoke. That realization might create an interest in smoke abatement in people now indifferent though suffering from the depreciation in value of urban property due to a flight to the suburbs. In one of the papers read, Mr. Noel Carrington blamed the decay of civic spirit in large cities for the lukewarm interest in the smoke nuisance. Those who do not live near their work are prone to be indifferent about the conditions there.

The present activity in rebuilding cities offers an unprecedented chance of replacing smoky by clean fuel appliances, but generally speaking the opportunity is neglected. The opportunity is recognized by public health officials-as shown in Dr. A. S. M. Macgregor's paper on the work of his department in Glasgow ; but public opinion rarely gives adequate backing.
The development of flying has brought support to the movement from a now quarter. Flight-Lieut. H. M. Schofield's paper described with terse emphasis how aviation is hindered in Great Britain by atmospheric conditions.

There is no doubt that improvement has taken place in the matter of industrial smoke, but the advance is uneven. In many light industries, the spread in the use of gas and electricity has removed the need for boiler plants, and new factories are often smokeless. However, as H. G. Clinch described, there is often great difficulty in enforcing a high standard, and this is increased by the reluctance of employers to encourage and reward technical training among working stokers.

The heavy industries offer another problem, for generally they are protected by law from prosecution for unavoidable smoke. This exemption has generally deprived them of a strong incentive to seek to avoid smoke. As Mr. H. C. Armstrong said in his paper, Sheffield opinion held that their "steels could not be made without smoke". This was due to the recognized need for maintaining a reducing atmosphere in furnaces. That this could only be done by keeping smoking coal fires seemed so axiomatic as to need no investigation. Recent studies have largely destroyed the basis for this opinion, and new practices are developing in Sheffield and Rotherham, assisted by the development of the 'grid' conveying gas from the coke ovens to the steel works. Mr. Armstrong shows clearly that large technical and financial difficulties retard the rapid abolition of coal-fired furnaces, and that much depends on the availability of cheap gas. A definite amelioration can be looked for.

The same point follows from the examination of the problem of smoke in the clay industries by $\mathrm{E}$. Rowden and A. T. Green. It must have puzzled many to understand why the makers of artistic ceramic ware should be content to live in the atmosphere of the Potteries. The firing of clayware is, however, beset with peculiar technical problems which often demand the use of intermittent kilns. When these are fired by coal, smoke production is inevitable, but efforts are being made to diminish this. Headway is being made with the use of town gas-fired kilns when possible, but cost of fuel is a limiting factor.

These industrial examples show the need for making gaseous fuel cheap if industrial smoke is to be reduced. At the moment, the case of the South Metropolitan Gas Co. has brought forward prominently 